\title{
Evaluation of FSO and FTTH technologies using techno-economic and risk analysis
}

\author{
Theodoros Rokkas, Dimitris Katsianis, Thomas Kamalakis, Dimitris Varoutas and \\ Thomas Sphicopoulos
}

\author{
Theodoros Rokkas and \\ Dimitris Katsianis are both \\ based at the University of \\ Athens, Athens, Greece. \\ Thomas Kamalakis is \\ based at the Harokopeio \\ University of Athens, \\ Athens, Greece. \\ Dimitris Varoutas and \\ Thomas Sphicopoulos are \\ also based at the University \\ of Athens.
}

\begin{abstract}
Purpose - The purpose of this paper is to carry out a techno-economic evaluation of the business prospects of Free Space Optical (FSO) technology as an alternative last mile solution

Design/methodology/approach - The analysis is based on the results from the TONIC tool that takes into account parameters such as network topology, area characteristics, service demand, price evolution forecasting and calculates several economic figures-of-merits. Furthermore in order to analyze market and technologies uncertainties a thorough risk analysis has been performed
\end{abstract}

Findings - The results reveal that FSO technology could provide a viable alternative in cases where the existing duct availability is limited especially compared to the Fiber-to-the-Home (FFTH) solutions.

Originality/value - This paper studies two alternative last mile broadband technologies FSO and FTTH Keywords Broadband networks, Economics, Case studies, Prices

Paper type Research paper

\section{Introduction}

The growing demand for higher broadband services forces network operators to invest in new infrastructure and equipment in order to face the increased bandwidth requirements. The new multimedia services demand that optical technologies must migrate closer to the customer premises towards an optical access network. However this wide scale deployment of access networks is hurdled by the significant economic risk (Wright et al., 2004).Optical fiber installation in dense populated areas requires costly civil works that affect the viability of the business project. Although, in areas where a large amount of ducts already exists (such as in many Western European countries), Fiber-to-the-Cabinet (FTTC) could provide a viable access solution in contrast to the Fiber-to-the-Home (FTTH) whose investment prospects are severely limited due to the enormous fiber roll-out (Monath et al., 2003). As shown later in this paper, duct availability affects significantly the prospects of FTTH scenarios. In these cases of limited duct availability other broadband technologies may benefit and rate more favourably compared to FTTH deployment strategy. One of this possible alternative solutions are systems based on free space optical (FSO) technology (Kedar and Arnon, 2004) as there are already commercially available products that can operate at rates of Gb/s. FSO systems has the advantage of easy installation on rooftops, signs, street lamps or even behind office windows due to their light weight and small dimensions. Furthermore, no license fees are necessary since the available spectrum is vast (from $0.7 \mu \mathrm{m}$ to $10 \mu \mathrm{m}$ ) and there is relatively limited beam spreading preventing interference. Areas with hot or mild climates where the probability of heavy fog occurrence is rather limited are ideal for the deployment of FSO systems. In regions with high probability of fog, a backup millimeter wave (MMW) link can also be used to achieve increased link availability exceeding 99.9 percent (Leitgeb et al., 2004). In this paper, a systematic and detailed study of the 
investment potential of FSO technology is carried out and compared to FTTH alternatives. Similar study between FSO and FTTC was carried out in the PIMRC 07 conference paper (Rokkas et al., 2007a). It is shown that in cases where duct availability is limited, FSO-based scenarios could provide an economically favourable alternative to fiber-based access scenarios. Various business aspects are also highlighted. Earlier version of the results present hereafter has been presented in CTTE 2007 conference (Rokkas et al. 2007b).

For the evaluation of different investment scenarios various indicatores like payback period and net present value (NPV) are used. In most of the cases these evaluations have some less accurate inputs. So it is advisable to apply sensitivity analysis and/or risk assessment methodologies using multiple figures of merit as indicators.

\section{Techno-economic modeling}

\section{General assumptions}

The purpose of techno-economic modeling is to analyze the economic profitability of certain network deployment scenarios. Quantitative techno-economic models are constructed, combining market and service related parameters and forecasts with cost and performance related parameters of the analyzed technologies. In most of long-term analyses, a study period of at least seven years is used. The study period assumed in this paper is eight years long, with starting and ending year 2008 and 2015 respectively. For all the cases the discount ratio is 10 percent and taxes are not been considered.

In order to estimate the required network components a geometric model is used. The areas are classified into dense urban, urban and suburban with different characteristics in terms of subscriber density, loop lengths, geographical and market characteristics.

The network model for all areas is based on the Metropolitan Access Network (MAN), connecting the Central Exchange (CEx) to the customers through the Local Exchange (LEx) and cabinets close to the buildings (Figure 1). In the same figure there also presented different part of the networks that FSO elements can be installed. The characteristics of the three area types are summarized in Table $I_{\text {, where }} I_{1}$ and $I_{2}$ are the maximum

Figure 1 The network architecture - scenarios

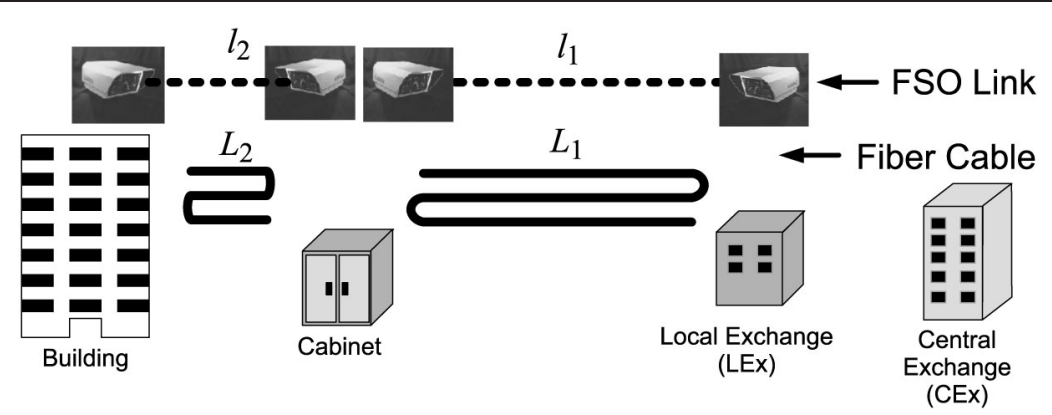

\section{Table I Area characteristics}

\begin{tabular}{lccc} 
Area type & Dense urban & Urban & Suburban \\
\hline $\mathrm{L}_{1}(\mathrm{Km})$ & 1.2 & 1.9 & 3.0 \\
$\mathrm{~L}_{2}(\mathrm{Km})$ & 0.2 & 0.3 & 0.4 \\
$\mathrm{I}_{1}(\mathrm{Km})$ & 1.2 & 2.0 & 3.2 \\
$\mathrm{I}_{2}(\mathrm{Km})$ & 0.08 & 0.13 & 0.20 \\
$\mathrm{~N}_{\mathrm{b}}$ & 1,024 & 2,048 & 16,384 \\
$\mathrm{n}_{\mathrm{sb}}$ & 64 & 32 & 4 \\
$\mathrm{~d}_{\mathrm{s}}\left(\right.$ subscriber $\left./ \mathrm{Km}^{2}\right)$ & 5,641 & 2,048 & 410
\end{tabular}


cabinet-building and LEx-Cabinet distances respectively (for FSO installation), $L_{1}$ and $L_{2}$ are the average cabinet-building and LEx-Cabinet duct lengths (for fiber optics installation) respectively, $d_{s}$ the subscriber density per square $\mathrm{km}, \mathrm{N}_{\mathrm{b}}$ the number of buildings in each area type and $n_{s b}$ the number of subscribers per building. A detailed description of area market model and the broadband services considered can be found in Monath et al. (2003).

\section{Techno-economic methodology}

The techno-economic methodology used for the evaluation of FSO technology is based on the TONIC tool developed within the IST-TONIC and the CELTIC/ECOSYS European projects. TONIC is a spreadsheet-based application that has been developed within the European Union Information Society Technologies (IST) program and is an implementation of the methodology developed by a series of previous projects in the field of telecom networks. The tool has been extensively used in several techno-economic studies among major European telecom organizations and academic institutes.

TONIC consists of a dimensioning model for different architectures that is linked to a database containing the various network elements and the cost evolution of them over time. The tool calculates revenues, cash balance, investments, cash flows and other financial results for the network architectures for each year of the study period. By combining these with other economic inputs (e.g. discount rate, tax rate) TONIC calculates outputs such as annual and cumulative cash flows, NPV, IRR, payback period and other of economic figure of merits. The NPV is a single figure of merit for the project. Its definition is the sum of discounted cash flows plus discounted rest value of the project. it gives the monetary value of the whole project in today's money. It is a good indicator for the profitability of the scenario especially in these cases where the payback period cannot be used because major investments are spread out in time.

In order to estimate the number of network components required throughout the study period, broadband access forecasts are carried out according to the methodology of (Stordahl et al., 1998) and revenues, investments, cash flows and other financial results for each year are calculated based on the broadband tariff structure of Stordahl et al. (1998). The operation administration and maintenance (OA\&M) costs for each of the network component are estimated based on an architectural model (Monath et al., 2003). The price evolution of the network components is estimated using the extended learning curve model as in (Stordahl et al., 1998). The cost of repairing parts is calculated according to the investments in network elements while the cost of repair work is calculated based on mean time between failure (MTBF) and the mean time to repair (MTTR) figures.

\section{Risk analysis}

Since the traditional approach is often unable to capture the flexibility of the decision-makers to adapt and revise later decisions in response to unexpected market developments, risk analysis has been carried out for the improvement of the analysis subject to adopted assumptions. Many of the assumptions of the variables that where chosen are uncertain and the variation of them may have a great impact on the project. In order to minimize the uncertainties a suitable probability density function should be associated with each of the most critical variables. In business cases usually Beta and Log Normal distributions are used to model the crucial parameters. In Monte Carlo simulation random numbers following a distribution are generated in each trial for each input variable and the selected output is then computed (Elnegaard and Stordahl, 2004).

\section{FTTH scenario}

The impact of duct availability to the deployment of fiber for FTTH scenario is provided in Figure 2 where we have calculated the NPV for all the available types of areas and for various values of existing duct availability $\left(d_{a}\right)$ assuming an eight year study period. 
Figure 2 NPV versus duct availability $d_{a}$ for FTTH scenario

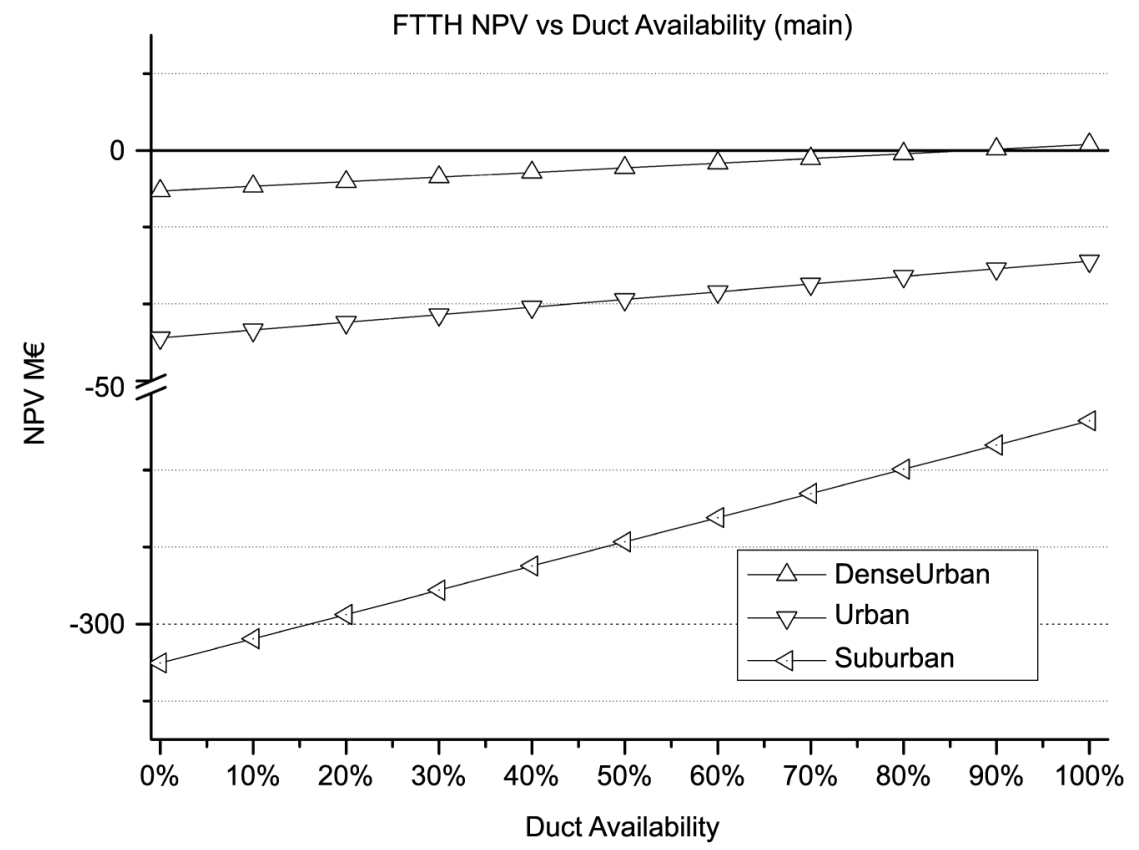

As expected, $d_{a}$ severely affects the business prospects of the investment and for $d_{a}=0$, this is the case of a green field when the operator has no ducts and cable installed in a specific area. In the suburban areas the NPV becomes positive only if the availability of the existing duct is above 80 percent, however this value is a typical value for most of the Western European Countries (Monath et al., 2003). NPV becomes positive for values above 40 percent and 90 percent for dense urban and urban areas respectively.

The above results illustrate the main issue that the operators face concerning the deployment of optical networks especially in the countries that the existing infrastructures are limited, for example developing countries. In these cases other alternative technologies such as FSO can de used especially in the access network providing the customers high broadband connections.

\section{FSO deployment cases}

FSO links can be installed in different combinations in order to connect the building or the cabinet with the local exchange.

To investigate the business aspects of FSO technology for wide spread deployment in the access network, two alternative scenarios are considered taking into consideration the lengths from Table I and the limitations of the current available commercial FSO components regarding the distance and the achieved rate (Table II).

1. FSO Long Range (LR) scenario. A number of relatively long range Gigabit FSO links (GFSOLR) with Automatic Gain Control (AGC) for increased reliability are deployed to

\section{Table II FSO link characteristics}

\begin{tabular}{lcccc} 
Designation & Maximum range $(m)$ & Interface & AGC option & Retail price 2008 $(€)$ \\
\hline GFSOLR & 1,500 & GbE & Yes & 18,000 \\
GFSOSR & 200 & GbE & No & 8,000
\end{tabular}


connect the LEx and the Cabinet, GFSOLR are also used to provide wireless Gigabit connections between the buildings and the cabinet.

2. FSOSR short range (SR) scenario. The Cabinet/customer connections have been established using the less expensive, shorter range Gigabit FSO links (GFSOSR) without AGC.

The link maximum range and retail price of the FSO links are summarized in Table II, these values are based on information available from various FSO link vendors. For each link a $1,500 €$ initial installation cost was assumed, while the values of MTBF and MTTR were taken ten years and eight hours respectively. As with all other network component, the model assumes that FSO links experience a price reduction estimated based on the extended learning curve.

As with any other network component, the model assumes that FSO links experience a price reduction estimated based on the extended learning curve. In the context of the TONIC methodology this price reduction is specified using the growth period $\Delta T$ (i.e. the time taken for the total production volume to reach from 10 percent to 90 percent of its maximum value), the learning coefficient $K$ (i.e. the price reduction experienced when the production volume is doubled) and the relative initial production volume $n_{r}(0)$ (Katsianis et al. 2001). For the FSO components, the values for these parameters must be postulated since not enough historical data are available in order to perform regression. Taking into account the guidelines in Katsianis et al. (2001), the values $K=0.8, \Delta T=5$ years and $n_{r}(0)=10^{-3}$ were selected for FSO links.

\section{Results and comparison}

\section{General results}

The results for FSOLR and FSOSR scenarios as alternative solutions to FFTH are presented at Table III where the NPVs for all the scenarios for the eight year study period in a dense urban area with $d_{a}=0$ (corresponding to limited previous investments) or $d_{a}=70$ percent (corresponding to increased previous investments) is listed. For the FSO scenarios the initial retail prices quoted in Table II were used for the NPV calculations. Both FSO Lex-Building scenarios result in greater NPVs from FTTH if $d_{a}=0$.

From the previous remarks we can assume that FSO technology can be an alternative of fiber technologies since it can lead to more favourable business opportunities compared to its fiber counterpart, especially if no trenches for fiber ducts have been digged up. On the other hand fiber-based scenarios are better than their FSO alternatives if $d_{a} \geq 70$ percent which is usually the case in most west European countries.

The cumulative cash flows for all the studied scenarios were calculated assuming no duct availability $(\mathrm{da}=0)$. The results reveal that the FSOSR case has less loses from FSOLR with the FTTH to be the worst case of all (Figure 3).

\section{Comparison of FTTH and FSOSR}

From the previous results we conclude that the competing scenario for FFTH (with no existing duct availability is the FSOSR. So we study the case of a country that is developing

\section{Table III Economic results for all scenarios}




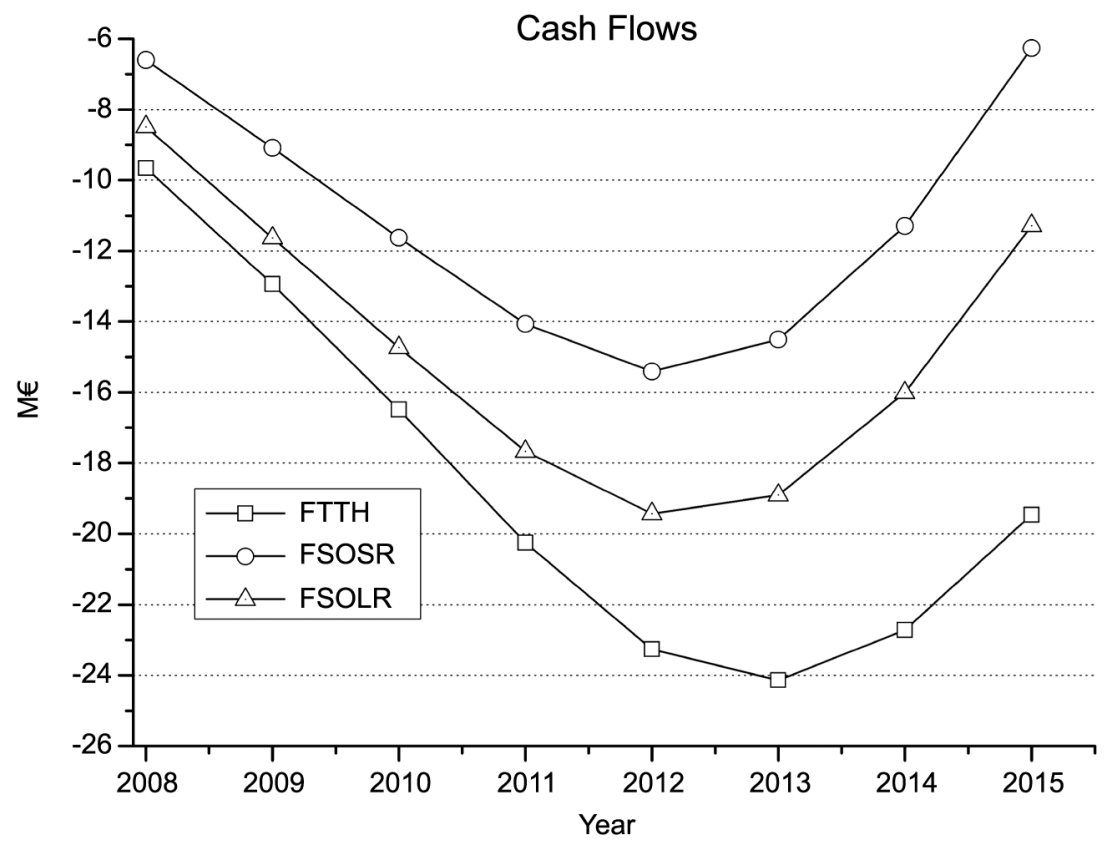

in terms of telecom infrastructures or the case of a Greenfield operator, meaning an operator that does not posses network elements and wants to build his own at dense urban areas.

In order to highlight the differences the annual revenues and lifecycle cost of the network for both the above mentioned cases have been calculated using the broadband tariff structure presented in (Stordahl et al., 1998) and plotted at Figures 4 and 5, furthermore in the FTTH scenario the investments are broken down to fiber installation costs (dark grey colour bar) and other network component related investments (light grey colour bar).

While in the FSOSR scenario, a similar breakdown is made and the dark grey colour bars correspond to investments in FSO links, while the rest of the investments are depicted with a light grey colour bar. The running costs are composed of component maintenance, personnel salaries, and O\&A costs. The annual cash flows are calculated by subtracting the sum of the investments and running costs from the revenues. The cumulative cash flows (cash balance) at a given year are calculated as the sum of the cash flows at that year and at all preceding years.

We must note that in both scenarios most of the investments (fiber is deployed for FTTH and optical links for FSOSR scenarios) are made in the first year (2008) of the project in order to cope with the expected coverage demand. However operators may benefit from the fact that FSO investments are reduced compared to the fiber installation as one can see from the comparison of the two figures. In addition because there will be mass installation of FSO components vendors can offer a substantial discount to operators. Furthermore the breakdown of the total investments for the whole study period reveals a reduction, by a factor of about 40 percent calculated from the savings due to the FSO links comparing to the sum of duct and cables costs. Contrarily fiber installation prices do not decline since a significant part of the cost is associated with costly civil works.

\section{Risk analysis}

In order to analyze the uncertainties Risk analysis performed for FSOSR and FTTH scenarios. The tariff, broadband penetration, price of FSO components and network 


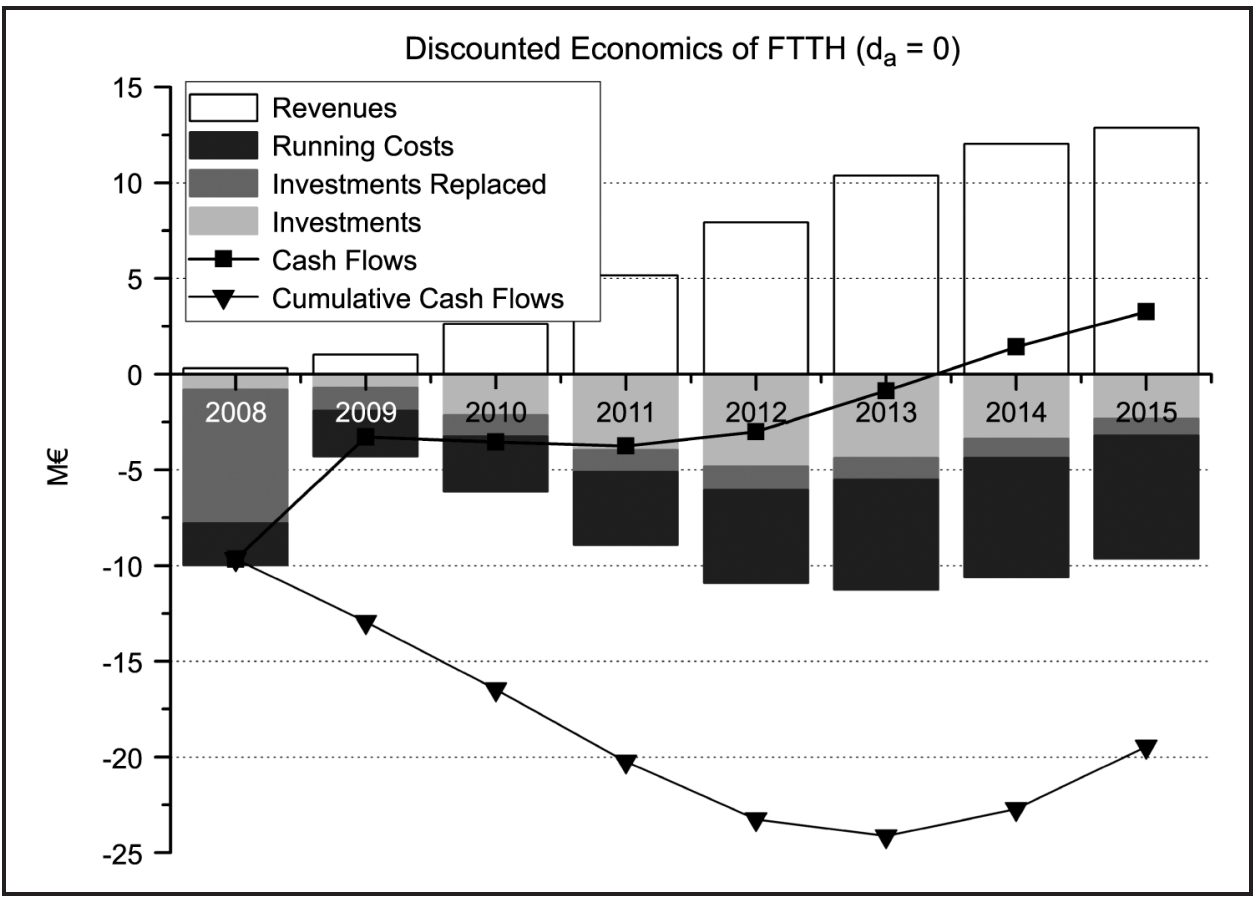

Figure 5 Revenues and cost breakdown analysis for the FSOSR scenario

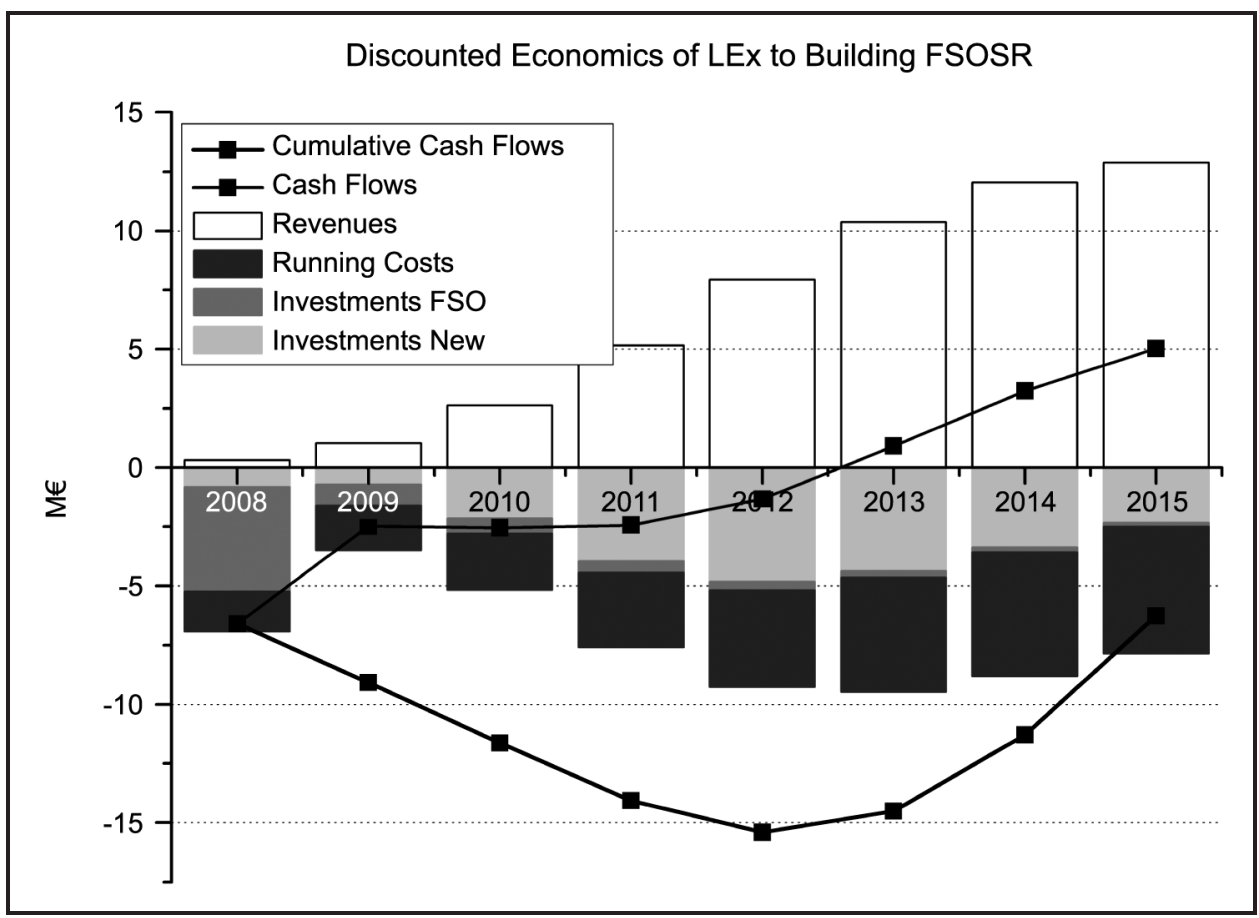

operation cost where identified as parameters with the greatest impact to the project and each of these variables was modelled by beta probability (no negative values) density function following the uncertainty assumptions presented in Table IV. For each of the selected parameter, the default value, the upper and lower limits, the optimistic, the 
Table IV Input parameters distribution

\begin{tabular}{lcccccc} 
Variable & $\begin{array}{c}\text { Most probable } \\
(\%)\end{array}$ & $\begin{array}{c}\text { Min. dist } \\
(\%)\end{array}$ & $\begin{array}{c}\text { Pessimistic } \\
(\%)\end{array}$ & $\begin{array}{c}\text { Optimistic } \\
(\%)\end{array}$ & $\begin{array}{c}\text { Max. dist } \\
(\%)\end{array}$ & $\begin{array}{c}\text { Confidence } \\
\text { (\%) }\end{array}$ \\
\hline Tariff & 100 & 70 & 80 & 105 & 110 & 90 \\
Penetration & 100 & 90 & 95 & 120 & 120 & 90 \\
Components price & 100 & 60 & 80 & 110 & 120 & 90 \\
Network cost & 100 & 80 & 90 & 110 & 120 & 90
\end{tabular}

pessimistic value and the confidence interval are determined. The distribution of these parameters was the input for a Monte Carlo simulation with 1,000 samples in each case and the output variable in order to evaluate the financial value of the project is the net present value (NPV).

Table $\mathrm{V}$ summarizes the results from all the simulations in terms of mean value, standard deviation, minimum and maximum values and percentage of cases above the base case. From the comparison we notice that FSOSR has higher mean value and lower standard deviation comparing to FTTH making this case less risky. Furthermore the mean to standard deviation ratio was calculated for both cases and is also higher in FSOSR scenario.

In Figure 6 the results from the risk analysis for FSOSR are presented where we can see that almost 37 percent off the cases will have better results than the base case while the value for FSOLR with a similar (figure not presented) case is 30 percent.

From Table VI we extract that in both scenarios the parameter with the greatest influence to variance is the tariff following by network operation costs, FSO component price (not applicable to FFTH) and services penetration. The dominant parameter that influences the variation in the results is therefore the uncertainty in tariff prices, the distribution that was selected considers that the values is more probable to decline than to rise from the initial values, if this happens then the scenarios will become even more worst than the base cases.

\section{Conclusion}

In this paper, a techno-economic evaluation of FSO (short and long range cases) and FTTH technologies in the access network was carried out. Using key economic figure of merits, it was shown that in areas which duct availability is limited FSO can provide an interesting, economically viable broadband alternative to FTTH. This is due to the fact that FSO installation does not require any costly civil works, which are the main cost factor in FTTH cases. In addition Risk Analysis evaluation shows that investment in FSO technology has less risk compared to the FTTH cases.

\section{Table V Results from the risk analysis simulations}

\begin{tabular}{lcc} 
NPV/Scenario & FTTH & FSOSR \\
\hline Mean (M€) & -15.03 & -3.73 \\
Standard deviation (M€) & 21.05 & 20,88 \\
Mean to standard deviation ratio & -0.71 & -0.18 \\
Minimum (M€) & -76.08 & -70.41 \\
Maximum (M€) & 65.25 & 69.47 \\
Percentage of simulations above the base case & 30 & 37
\end{tabular}




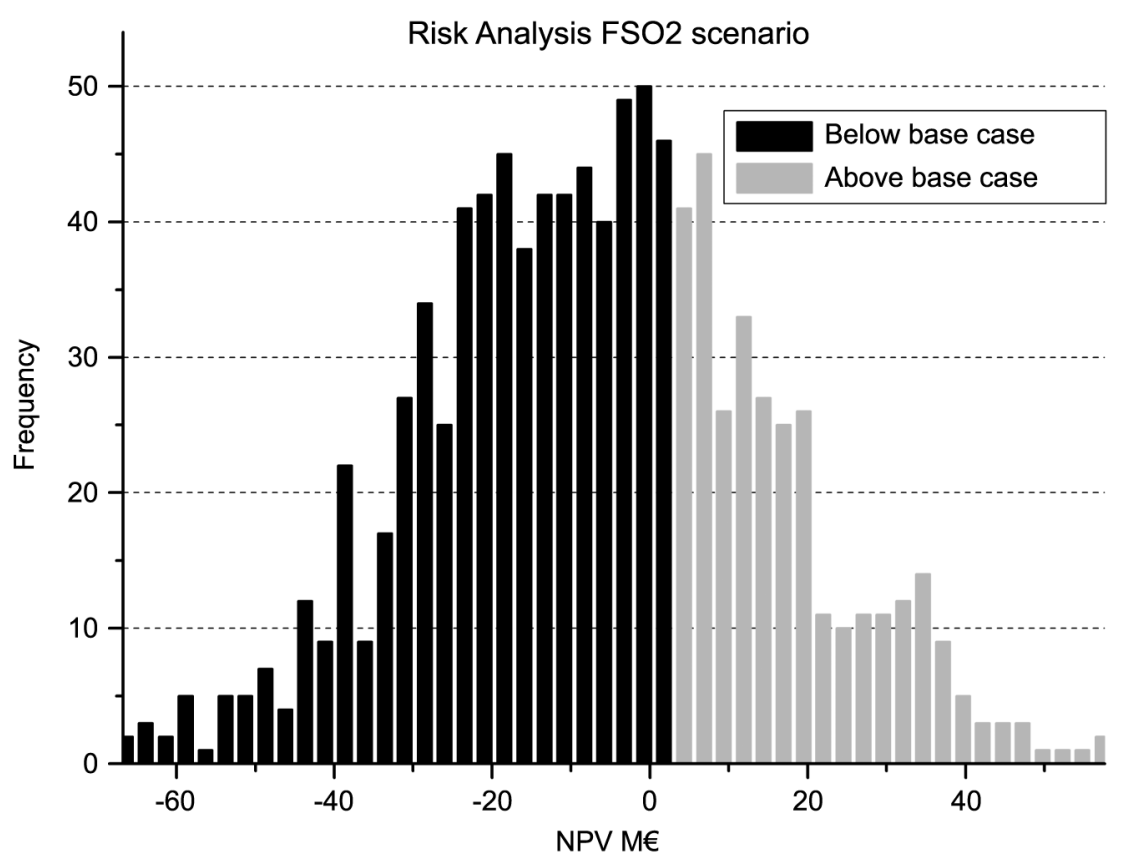

Table VI Contribution to variance

Variable

FTTH (\%)

FSOSR (\%)

Tariff

83

84

Network operation

$-16$

$-11$

Components price

Penetration

$-$

$-4$

\section{References}

Elnegaard, N.K. and Stordahl, K. (2004), "Analysing the impact of forecast uncertainties in broadband access rollouts by the use of risk analysis", Telektronikk, Vol. 4 No. 2004, pp. 157-67.

Katsianis, D., Welling, I., Ylonen, M., Varoutas, D., Sphicopoulos, T., Elnegaard, N., Olsen, B. and Budry, L. (2001), "The financial perspective of the mobile networks in Europe", IEEE Personal Communications, Vol. 8 No. 6, pp. 58-64.

Kedar, D. and Arnon, S. (2004), "Urban optical wireless communication network: the main challenges and possible solutions", IEEE Communication Magazine, Vol. 42 No. 5, pp. S2-S7.

Leitgeb, E., Gebhart, M., Birnbacher, U., Kogler, W. and Schrotter, P. (2004), "High availability of hybrid wireless networks", Proceedings of SPIE, Vol. 5465, pp. 238-49.

Monath, T., Elnegaard, N.K., Cadro, P., Katsianis, D. and Varoutas, D. (2003), "Economics of fixed broadband access network strategies", IEEE Communication. Magazine, Vol. 41 No. 9, pp. 132-9.

Rokkas, T., Kamalakis, T., Katsianis, D., Varoutas, D. and Sphicopoulos, T. (2007a), "Business prospects of wide-scale deployment of free space optical technology as a last-mile solution: a techno-economic analysis", Proceedings 18th IEEE Annual International Symposium on Personal Indoor and Mobile Radio Communications (PIMRC 2007), 3-7 September 2007, Athens, Greece.

Rokkas, T., Kamalakis, T., Katsianis, D., Varoutas, D. and Sphicopoulos, T. (2007b), "Free space optical technology as an alternative last-mile solution: a techno-economic analysis" Proceedings 6th Conference on Telecommunication TechoEconomics CTTE 2007, 14-15 June 2007, Helsinki. 
Stordahl, K., Ims, L.A., Elnegaard, N.K., Azevedo, F. and Olsen, B.T. (1998), "Broadband access network competition - analysis of technology and market risks" Proceedings of Globecom, Sydney, 8-12 November 1998.

Wright, S., Fahmy, H. and Vernon, A.J. (2004), "Deployment challenges for access/metro optical networks and services", IEEE Journal of Lightwave Technology, Vol. 22 No. 11, pp. 2606-16.

\section{Further reading}

ECOSYS (n.d.), "Techno-ECOnomics of integrated communication SYStems and services", available at: www.celtic-ecosys.org

Olsen, B. and Stordahl, K. (2004), "Models for forecasting cost evolution of components and technologies", Telektronikk, Vol. 100, pp. 138-48.

TONIC (n.d.), "Techno-economics of IP optimised networks and services", available at: www.nrc.nokia. com/tonic

Varoutas, D., Katsianis, D., Sphicopoulos, T., Loizillon, F., Kalhagen, K.O., Stordahl, K., Welling, I. and Harno, J. (2003), "Business opportunities through UMTS-WLAN networks", Annales des Telecommunications, Vol. 58, pp. 553-75.

To purchase reprints of this article please e-mail: reprints@emeraldinsight.com Or visit our web site for further details: www.emeraldinsight.com/reprints 